\title{
PRODUÇÃO DE BIOMASSA E TEOR DE MACRONUTRIENTES DO MILHETO, FEIJÃO-DE-PORCO E GUANDU-ANÃO EM CULTIVO SOLTEIRO E CONSORCIADO ${ }^{1}$
}

\author{
Biomass production and macronutrients quantity of millet, jack bean, \\ guandu single and in intercropping
}

\author{
Cícero Monti Teixeira ${ }^{2}$, Gabriel José de Carvalho ${ }^{3}$, Antônio Eduardo Furtini Neto ${ }^{4}$, \\ Messias José Bastos de Andrade ${ }^{3}$, Edson Luiz Silva Marques ${ }^{5}$
}

\begin{abstract}
RESUMO
Objetivou-se determinar a produção de biomassa e o teor de macronutrientes do milheto (Pennisetum typhoides (Burm.) Stapf), feijão-de-porco (Canavalia ensiformes (L.) DC.) e guandu-anão (Cajanus cajan (L.) Millsp.) em cultivo solteiro e nos consórcios da gramínea com as leguminosas, visando a produção de palha no sistema plantio direto. O trabalho foi conduzido no campo experimental do Departamento de Agricultura da Universidade Federal de Lavras (Lavras, MG, Brasil). O delineamento foi o de blocos casualizados, com cinco tratamentos e quatro repetições. Apenas o guandu-anão solteiro apresentou menor produção de fitomassa fresca e seca, sendo que os demais tratamentos não diferiram entre si, pelo teste de Tukey a $5 \%$ de probabilidade. De forma geral, as leguminosas apresentaram maiores teores de $\mathrm{N}$ e Ca e o milheto maiores teores de S. Apenas o feijão-de-porco solteiro apresentou menor teor de $\mathrm{P}$. Os maiores teores de $\mathrm{K}$ foram apresentados pelo milheto solteiro e consorciado com as leguminosas e pelo feijão-de-porco em consórcio com milheto. Os menores teores de Mg foram verificados para o guandu-anão.
\end{abstract}

Termos para indexação: plantio direto, adubação verde, reciclagem de nutrientes.

\begin{abstract}
The object of this work was to evaluate the biomass production and the macronutrients quantity of millet (Pennisetum typhoides (Burm.) Stapf), jack bean (Canavalia ensiformes (L.) DC.), guandu (Cajanus cajan, (L.) Millsp.) dwarf cultivar, and the millet with leguminous consortiums to straw production in no-tillage system. The experiment was carried in experimental area at Agriculture Department of the Federal University of Lavras (Lavras, Minas Gerais state, Brazil). The experimental design was randomized blocks, with five treatments and four replications. For biomass production, only the guandu presented smaller fresh and dry biomass yield than the other treatments. In general, the leguminous presented the greatest $\mathrm{N}$ and Ca quantities and millet the greatest quantities of S. Only jack bean presented minor $\mathrm{P}$ quantity. For $\mathrm{K}$ the greatest quantities were verified for single milett and its incropping with leguminous and jack bean in intercroppin with millet. The minor quantities of $\mathrm{Mg}$ were observed for guandu.
\end{abstract}

Index terms: no-tillage, green manuring, nutrients recycle.

(Recebido para publicação em 27 de abril de 2004 e aprovado em 3 de novembro de 2004)

\section{INTRODUÇÃO}

Com a expansão do plantio direto, a experiência dos produtores e as pesquisas realizadas, constatou-se que a rotação/sucessão de culturas era fundamental para a viabilidade do sistema, devendo ser baseada, entre outros fatores na utilização do solo, tanto química quanto fisicamente, devido às diferenças de exigência nutricional e exploração pelo sistema radicular das diferentes espécies; e no potencial de produção de palha das culturas, sejam elas comerciais, aproveitando os restos culturais, ou semeadas exclusivamente para este fim.
Na Região Sul, o inverno chuvoso permite a implantação de cultivos de inverno para a produção exclusiva de palha ou a produção de grãos, com alta quantidade de restos culturais como o trigo, centeio, cevada e aveia. Além desse fator, naquela região, o verão com temperaturas mais amenas, aumenta a longevidade do material sobre a superfície do solo, permitindo o uso de leguminosas, as quais possuem relação carbono/nitrogênio mais baixa, introduzindo nitrogênio no sistema pela fixação biológica do elemento.

\footnotetext{
1. Parte da dissertação de mestrado apresentado à Universidade Federal de Lavras/UFLA - Caixa Postal 3037 - $37.200-000$ - Lavras, MG, pelo primeiro autor.

2. Engenheiro Agrônomo, Doutorando em Agronomia, Fitotecnia/UFLA. Bolsista da CAPES.

3. Engenheiro Agrônomo-DSc, Professor Adjunto do Departamento de Agricultura/UFLA.

4. Engenheiro Agrônomo-DSc, Professor Adjunto do Departamento de Ciência do Solo /UFLA.

5. Acadêmico do $6^{\circ}$ módulo de Agronomia/UFLA.
} 
Já nos cerrados, a produção e manutenção de altas quantidades de palha sobre a superfície tornam-se um pouco mais difíceis, devido ao fato dessas regiões possuírem duas estações bem definidas, com seis meses de chuva e muito calor na primavera/verão e seis meses de estiagem no outono /inverno. Nesse caso a produção de palha fica restrita aos cultivos em safrinha, aproveitando as últimas chuvas do mês de março após a cultura de verão, associados à culturas com grandes quantidades de restos culturais como o milho. Nessas condições, as altas temperaturas do verão restringem o uso de leguminosas para produção de palha devido à rápida decomposição, tornando-se uma opção viável a utilização de consórcios entre gramíneas e leguminosas, o que ainda necessita de estudos para se identificar as melhores combinações entre espécies.

Para Giacomini et al. (2003), além de proteger o solo e de adicionar nitrogênio, o consórcio entre espécies de plantas de cobertura de solo deve proporcionar uma produção de matéria seca cuja relação $\mathrm{C} / \mathrm{N}$ seja intermediária àquela das espécies em culturas isoladas, proporcionando cobertura de solo por mais tempo e sincronia entre fornecimento e demanda de $\mathrm{N}$ pelas culturas comerciais.

Alguns trabalhos foram realizados na Região Sul do Brasil com plantas de cobertura no cultivo de outono/inverno, no sentido de se identificar as melhores combinações de espécies e proporções de sementes para implantação dos consórcios. Neste sentido alguns autores como Amado et al. (2000), Amado e Mielniczuk (2000) e Basso e Ceretta (2000) atestaram a eficiência do consórcio entre gramíneas e leguminosas de inverno na Região Sul, para o fornecimento ou menor imobilização de nitrogênio para a cultura principal, associado à maior durabilidade da camada de palha sobre a superfície no plantio direto.

Diante disso, objetivou-se determinar a produção de biomassa e o teor de macronutrientes dos consórcios e do cultivo isolado das plantas de cobertura com semeadura em março, utilizando gramíneas e leguminosas.

\section{MATERIAL E MÉTODOS}

O trabalho foi conduzido no campo experimental do Departamento de Agricultura da Universidade Federal de Lavras, no período de março a julho de 2003, em um Latossolo Vermelho distroférrico típico (EMBRAPA, 2000), com as seguintes características na camada arável: $\mathrm{pH}$ em água (1:2,5) 5,2; $11,7 \mathrm{mg} \mathrm{dm}^{-3} \mathrm{de}$ P; $63 \mathrm{mg} \mathrm{dm}^{-3}$ de K; $1,3 \mathrm{cmol}_{\mathrm{C}} \mathrm{dm}^{-3} \mathrm{de} \mathrm{Ca} ; 0,7 \mathrm{cmol}_{\mathrm{c}} \mathrm{dm}^{-3}$ de $\mathrm{Mg} ; 0,3 \mathrm{cmol}_{\mathrm{C}} \mathrm{dm}^{-3}$ de $\mathrm{Al}$ e 2,4 dag kg-1 de matéria orgânica. $\mathrm{O}$ delineamento utilizado foi o de blocos casualizados, com cinco tratamentos e quatro repetições. As parcelas foram constituídas por dez linhas espaçadas de $0,5 \mathrm{~m}$ com $10 \mathrm{~m}$ de comprimento, sendo utilizadas como área útil seis linhas de $2 \mathrm{~m}$ na área central da parcela $\left(6 \mathrm{~m}^{2}\right)$. Os tratamentos foram compostos pela semeadura das plantas de cobertura em cultivo solteiro e consorciado. Os consórcios foram constituídos por linhas alternadas, com o mesmo número de plantas por metro linear das espécies em cultivo solteiro e semeadura simultânea das duas espécies. Para implantação do experimento procedeu-se o preparo convencional da área (aração e gradagem), seguindo o sulcamento no espaçamento determinado. A distribuição das sementes foi feita manualmente, haja vista a utilização de diferentes espécies.

O feijão-de-porco e o guandu-anão foram semeados na densidade de 8 e 18 sementes por metro linear, respectivamente. Para o milheto foi utilizada uma densidade de $15 \mathrm{~kg} \cdot \mathrm{ha}^{-1}$.

A avaliação das plantas de cobertura foi realizada 119 dias após a semeadura, quando o milheto se encontrava no estádio de grão leitoso a farináceo. O feijão-de-porco encontrava-se em floração plena e o guandu-anão no início da floração. Foram avaliados a produção de fitomassa verde e seca e o teor de nutrientes das plantas de cobertura em cultivo solteiro e consorciado. Nos consórcios, as plantas foram pesadas separadamente para avaliação do seu comportamento nos cultivos solteiro e consorciado.

Para determinação da produção de fitomassa seca foi obtido o teor de matéria seca, retirando-se uma amostra de aproximadamente $500 \mathrm{~g}$ de cada parcela (ou duas no caso dos consórcios), as quais foram secas em estufas de circulação forçada a $65^{\circ} \mathrm{C}$ até atingirem peso constante (OLIVEIRA, 2001). As amostras retiradas para avaliação do teor de matéria seca, após a secagem em estufa, foram moídas em moinho tipo Wiley e enviadas ao Laboratório de Análise Foliar do Departamento de Química da Ufla, para determinação dos teores de N, P, $\mathrm{K}, \mathrm{Ca}, \mathrm{Mg}$ e S da parte aérea das plantas de cobertura (MALAVOLTA et al., 1997).

\section{RESULTADOS E DISCUSSÃO}

\section{Produção de fitomassa verde e seca}

Pelo resumo das análises de variância (Tabela 1 ), verifica-se que houve significância $(p<0,01)$ dos tratamentos na produção de fitomassa fresca e seca. Entre os tratamentos, apenas o guandu-anão em cultivo solteiro apresentou menor produção, tanto de fitomassa fresca como seca, não sendo os demais diferentes estatisticamente (Tabela 2). 
TABELA 1 - Resumo da análise de variância dos dados referentes à produção de fitomassa fresca e seca do milheto, feijão-de-porco e guandu-anão e dos consórcios da gramínea com as leguminosas. UFLA, Lavras, MG, 2003.

\begin{tabular}{lccc}
\hline & & \multicolumn{2}{c}{ Quadrados Médios } \\
\cline { 3 - 4 } Fontes de variação & Graus de liberdade & Fitomassa fresca & Fitomassa seca \\
Tratamentos & 4 & $90,659490^{* *}$ & $4,112174^{* *}$ \\
Blocos & 3 & 2,719492 & 0,125504 \\
Erro & 12 & 4,639108 & 0,291789 \\
\hline \multicolumn{1}{c}{ C.V. (\%) } & & 20,73 & 22,34 \\
\hline
\end{tabular}

** Significativo no teste de $\mathbf{F}$ a $1 \%$

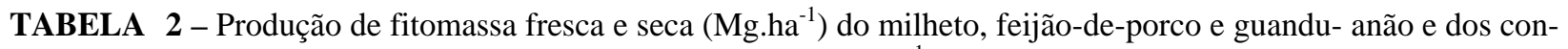
sórcios da gramínea com as leguminosas. UFLA, Lavras, MG, $2003^{1}$.

\begin{tabular}{lcccccc}
\hline \multirow{2}{*}{ Tratamentos } & \multirow{2}{*}{$\begin{array}{c}\text { Fitomassa } \\
\text { verde }\end{array}$} & \multicolumn{2}{c}{ Contribuição (\%) } & & \multicolumn{2}{c}{ Contribuição (\%) } \\
\cline { 3 - 4 } & & milheto & leguminosa & Fitomassa seca & milheto & leguminosa \\
FP+M & $14,171 \mathrm{a}$ & 44,7 & 55,3 & $3,275 \mathrm{a}$ & 51,4 & 48,6 \\
$\mathrm{M}$ & $11,729 \mathrm{a}$ & 100 & - & $2,907 \mathrm{a}$ & 100 & - \\
$\mathrm{FP}$ & $13,833 \mathrm{a}$ & - & 100 & $2,728 \mathrm{a}$ & - & 100 \\
$\mathrm{GA}+\mathrm{M}$ & $9,709 \mathrm{a}$ & 90,1 & 9,9 & $2,505 \mathrm{a}$ & 86,7 & 13,3 \\
$\mathrm{GA}$ & $2,500 \mathrm{~b}$ & - & 100 & $0,676 \quad \mathrm{~b}$ & - & 100 \\
\hline
\end{tabular}

${ }^{1}$ Médias seguidas de mesma letra, nas colunas, não diferem entre si pelo teste de Tukey a $5 \%$ de probabilidade. FP = feijão-de-porco, $M$ = milheto, $G A$ = guandu-anão.

No consórcio entre milheto e feijão-de-porco, a contribuição das espécies na produção total de fitomassa, tanto fresca como seca, foi praticamente a mesma, ao contrário do consórcio entre milheto e guandu-anão em que a predominância da fitomassa foi do milheto (Tabela 2). Esse resultado demonstra que o consórcio entre milheto e feijão-de-porco foi melhor nesta época, embora sua produção de fitomassa tenha sido aquém daquelas encontradas em Lavras, MG por Oliveira (2001), o qual obteve produções de 32,92 e 10,81 t.ha ${ }^{-1}$ de fitomassa fresca e seca respectivamente, porém, com semeadura em novembro. Diferentemente do presente trabalho, o autor obteve maior produção de fitomassa do milheto solteiro em relação ao consórcio com o feijão-de-porco, porém, os espaçamentos foram diferentes, com 0,25 m no solteiro e 0,80 m entre linhas de milheto no consorciado, e a semeadura da leguminosa 25 dias após a da gramínea, o que pode ter reduzido o desenvolvimento do feijão-de-porco.

Já no consórcio entre milheto e guandu-anão, a contribuição da leguminosa foi muito baixa em relação à gramínea (Tabela 2), o que aliado à baixa produção em cultivo solteiro mostra não ser recomendável para a região a semeadura desta espécie no outono. Porém, outros autores obtiveram com semeadura em março, valores superiores como Amabile (1996), que obteve 5,7 tha ${ }^{-1}$ e Santos e Carvalho (1999), que obtiveram produção próxima de 3,5 t.ha ${ }^{-1}$, com cultivar de porte alto. Esta baixa produção de fitomassa apresentada pelo guandu pode estar associada à temperaturas mais baixas ocorridas no período de desenvolvimento da cultura, já que a temperatura média ideal para seu desenvolvimento se encontra entre 20 e $30^{\circ} \mathrm{C}$ (CALEGARI et al., 1992). 
A produção de fitomassa seca do feijão-deporco em cultivo solteiro (Tabela 2) pode ser considerada baixa quando comparada a outros resultados, como os encontrados por Araújo e Almeida (1993), Ceretta et al. (1994), Alvarenga et al. (1995), Favero et al. (2000) e Carvalho (2000), que obtiveram produções entre 4,93 e 10,17 t.ha ${ }^{-1}$, porém, todos com semeadura na primavera, estando próxima das obtidas em Lavras na primavera por Oliveira (2001) com 3,43 t.ha ${ }^{-1} \mathrm{e}$ no outono por Santos e Carvalho (1999) com 3,5 t.ha ${ }^{-1}$.

O milheto solteiro apresentou uma produção de fitomassa baixa, não se inserindo nas produções alcançadas em Lavras na mesma época de plantio como em trabalho de Teixeira e Carvalho (1999), com 3,7 t.ha ${ }^{-1}$ de fitomassa seca, sem a utilização de irrigação, podendo ser considerada baixíssima quando comparada com produções de primavera/verão, como a encontrada por Oliveira (2001) de 14,18 t.ha ${ }^{-1}$. Esta baixa produção está associada ao florescimento precoce na cultura, ocorrido quando esta apresentava apenas $1 \mathrm{~m}$ de altura, aproximadamente 40 dias após a semeadura, o que pode estar associado a um período de baixas temperaturas no mês de abril, fato considerado atípico na região.

\section{Teor de macronutrientes}

Na Tabela 3 observa-se que houve significância $(\mathrm{p}<0,01)$ dos tratamentos nos teores de macronutrientes.

Observando-se os dados apresentados na Tabela 4 , verifica-se que os maiores teores de $\mathrm{N}$ foram obtidos pelas leguminosas, nas duas formas de cultivo, com destaque para o feijão-de-porco consorciado com o milheto. Esse resultado pode ser explicado pela rápida absorção de $\mathrm{N}$ por parte do milheto, esgotando o nutriente no solo e influenciando positivamente a fixação biológica pela leguminosa, conforme citaram vários autores compilados por Giacomini et al. (2003).
Salienta-se que os teores de $\mathrm{N}$ encontrados no feijão-de-porco (Tabela 4), se inserem naqueles verificados por Araújo e Almeida (1993), Ceretta et al. (1994), Alvarenga et al. (1995), Favero et al. (2000) e Oliveira (2001) que variaram entre 1,78 e 3,45 dag. $\mathrm{kg}^{-1}$.

No guandu-anão, os teores de $\mathrm{N}$ observados estão dentro da faixa encontrada por vários autores como Ceretta et al. (1994), Alvarenga et al. (1995), Favero et al. (2000), Alcântara et al. (2000) e Carvalho (2000) que é de 1,88 a 2,68 dag. $\mathrm{kg}^{-1}$, embora estes autores tenham utilizado cultivares de porte alto.

O milheto consorciado com guandu-anão apresentou uma tendência ao maior teor de N, quando comparado às outras formas de cultivo da gramínea. Esse fato, provavelmente se deve à menor competição por parte do guandu, já que este apresentou menor desenvolvimento entre as espécies estudadas (Tabela 2).

$\mathrm{O}$ maior teor de $\mathrm{P}$ foi observado no milheto em consórcio com o guandu-anão com 0,24 dag. $\mathrm{kg}^{-1}$ (Tabela 4), indicando menor competição do guandu com o milheto na absorção deste nutriente. O menor teor de $P$ foi verificado no feijão-de-porco solteiro e os demais tratamentos não diferiram significativamente dos teores extremos.

Os teores de $\mathrm{P}$ encontrados para o milheto foram muito próximos dos encontrados por Carvalho (2000) e Moraes (2001), com 0,25 e 0,24 dag. $\mathrm{kg}^{-1}$, sendo superiores aos encontrados por Oliveira (2001) de 0,18 dag. $\mathrm{kg}^{-1}$. Os teores de $\mathrm{P}$ do guandu-anão se inserem nos encontrados por Ceretta et al. (1994), Alvarenga et al. (1995), Alcântara et al. (2000), Carvalho (2000) e Favero et al. (2000), que estão entre 0,09 e 0,29 dag. $\mathrm{kg}^{-1}$, todos utilizando cultivares de porte alto. No feijão-de-porco, os teores de fósforo estão dentro da faixa verificada por vários autores, como Araújo e Almeida (1993), Ceretta et al. (1994), Alvarenga et al. (1995), Favero et al. (2000) e Oliveira (2001) que é de 0,07 a 0,24 dag.kg-1.

TABELA 3 - Resumo das análises de variância dos dados referentes aos teores de macronutrientes da parte aérea do milheto, feijão-de-porco e guandu-anão solteiros e consorciados, por ocasião do manejo. Ufla, Lavras, MG, 2003.

\begin{tabular}{|c|c|c|c|c|c|c|c|}
\hline \multirow{2}{*}{$\mathbf{F V}$} & \multirow{2}{*}{ GL } & \multicolumn{6}{|c|}{ Macronutrientes (quadrados médios) } \\
\hline & & $\mathbf{N}$ & $\mathbf{P}$ & $\mathbf{K}$ & Ca & Mg & $\mathbf{S}$ \\
\hline Tratamentos & 6 & $1,1216^{* *}$ & $0,0029 * *$ & $0,1804 * *$ & $2,1976 * *$ & $0,0045 * *$ & $0,0033^{* *}$ \\
\hline Blocos & 3 & 0,2562 & $0,0057 * *$ & $0,1804^{* *}$ & 0,1096 & 0,0016 & 0,0012 \\
\hline Erro & 18 & 0,0949 & 0,0010 & 0,0132 & 0,0428 & 0,0007 & 0,0006 \\
\hline CV (\%) & & 13,4 & 15,01 & 7,77 & 20,34 & 16,68 & 15,83 \\
\hline
\end{tabular}

** Significativo no teste de $\mathrm{F}$ a $1 \%$.

Ciênc. agrotec., Lavras, v. 29, n. 1, p. 93-99, jan./fev. 2005 
TABELA 4 - Teores de macro do feijão-de-porco, guandu-anão e milheto em cultivo solteiro e consorciado por ocasião do manejo. Ufla, Lavras, MG, $2003^{1}$.

\begin{tabular}{|c|c|c|c|c|c|c|}
\hline \multirow[t]{2}{*}{ Tratamentos } & \multicolumn{6}{|c|}{ Macronutrientes (dag.kg ${ }^{-1}$ ) } \\
\hline & $\mathbf{N}$ & $\mathbf{P}$ & $\mathbf{K}$ & Ca & Mg & $\mathbf{S}$ \\
\hline feijão-de-porco (cons.) & 3,05 a & $0,19 a b$ & $1,49 \mathrm{ab}$ & 1,99 a & $0,17 \mathrm{ab}$ & $0,14 \mathrm{~b}$ \\
\hline feijão-de-porco (solt.) & $2,67 \mathrm{ab}$ & $0,16 \mathrm{~b}$ & 1,38 bc & 2,09 a & $0,16 \mathrm{ab}$ & $0,13 \mathrm{~b}$ \\
\hline guandu-anão (solt.) & $2,57 \mathrm{ab}$ & $0,23 \mathrm{ab}$ & 1,22 с & $0,93 \mathrm{~b}$ & 0,09 с & $0,14 \mathrm{~b}$ \\
\hline guandu-anão (cons.) & $2,42 \mathrm{ab}$ & $0,22 \mathrm{ab}$ & 1,26 bc & $0,95 \mathrm{~b}$ & 0,13 bc & $0,14 \mathrm{~b}$ \\
\hline milheto (cons. guandu-anão) & 2,08 bc & $0,24 \mathrm{a}$ & $1,74 \mathrm{a}$ & 0,39 с & $0,17 \mathrm{ab}$ & $0,19 a b$ \\
\hline milheto (solt.) & $1,67 \mathrm{c}$ & $0,23 \mathrm{ab}$ & $1,75 \mathrm{a}$ & 0,38 с & $0,16 \mathrm{ab}$ & $0,15 a b$ \\
\hline milheto (cons. feij-de-porco) & $1,62 \mathrm{c}$ & $0,21 \mathrm{ab}$ & $1,51 \mathrm{ab}$ & $0,40 \mathrm{c}$ & $0,20 \mathrm{a}$ & $0,21 \mathrm{a}$ \\
\hline
\end{tabular}

Na Tabela 4 observa-se ainda que os maiores teores de $\mathrm{K}$ foram encontrados no milheto solteiro e em consórcio com o guandu-anão, com 1,75 e 1,74 dag. $\mathrm{kg}^{-1}$, respectivamente. O menor foi observado no guandu-anão solteiro.

É interessante observar que a competição imposta pelo feijão-de-porco no consórcio com o milheto, fez com que este apresentasse uma tendência a um menor teor de $\mathrm{K}$, quando comparado ao seu teor em cultivo solteiro (Tabela 4). Por outro lado, a presença do milheto parece ter beneficiado o feijão-de-porco, pois, este quando consorciado com o milheto, apresentou valor que não diferiu dos maiores teores, enquanto que em cultivo solteiro, o teor de K não diferiu do menor. Uma possível explicação é a lavagem de K no milheto, que se encontrava no final do ciclo, aumentando a concentração do elemento na camada superficial do solo e, conseqüentemente, nas plantas de feijão-de-porco. A mesma explicação pode justificar a tendência do guandu, em consórcio com milheto, a apresentar maior teor de $\mathrm{K}$ em relação a seu cultivo solteiro.

$\mathrm{O}$ teor de $\mathrm{K}$ encontrado para o milheto foi, em média, semelhante aos encontrados por Moraes (2001), de 1,72 dag.kg-1 e por Carvalho (2000), de 1,77 dag.kg${ }^{1}$, sendo inferior ao encontrado por Oliveira (2001) com 1,88 dag. $\mathrm{kg}^{-1}$. Os teores de $\mathrm{K}$ encontrados para o feijãode-porco se inserem nos verificados por Araújo e Almeida (1993), Ceretta et al. (1994), Alvarenga et al. (1995), Favero et al. (2000) e Oliveira (2001), os quais variam entre 0,82 e 2,13 dag. $\mathrm{kg}^{-1}$. O teor médio de $\mathrm{K}$ do guandu-anão foi superior ao encontrado por Alvarenga et al. (1995), com 1,01 dag. $\mathrm{kg}^{-1}$, bem acima do observado por Carvalho (2000) com 0,15 dag. $\mathrm{kg}^{-1}$ e semelhante ao encontrado por Ceretta et al. (1994), com 1,19 dag. $\mathrm{kg}^{-1}$, tendo todos os autores utilizado cultivares de porte alto.

Para o $\mathrm{Ca}$, os maiores teores foram verificados no feijão-de-porco solteiro e consorciado, seguido do guanduanão solteiro e consorciado e, por último, do milheto solteiro e nas duas formas de consórcio (Tabela 4). Resultado semelhante foi observado por Oliveira (2001), que encontrou maiores teores de Ca no feijão-de-porco e menor no milheto, assim como Carvalho (2000), que encontrou teor duas vezes maior de Ca no guandu em relação ao milheto.

Os teores de Ca encontrados para o feijão-deporco estão dentro da faixa observada por Araújo e Almeida (1993), Alvarenga et al. (1995), Favero et al. (2000) e Oliveira (2001), que é de 1,01 a 2,96 dag. $\mathrm{kg}^{-1}$. Os teores de Ca verificados para o guandu-anão assemelham-se ao encontrado por Carvalho (2000) com 0,99 dag. $\mathrm{kg}^{-1}$, e são superiores aos encontrados por Alvarenga et al. (1995), Favero et al. (2000) e Alcântara et al. (2000) com média de 0,43 dag. $\mathrm{kg}^{-1}$, todos utilizando cultivares de porte alto. Para o milheto, os teores estão próximos do observado por Carvalho (2000) de 0,49 dag. $\mathrm{kg}^{-1}$ e inferiores aos observados por Oliveira (2001) e Moraes (2001) de 0,7 e 1,09 dag.kg-1, respectivamente. 
O maior teor de $\mathrm{Mg}$ foi verificado no milheto consorciado com o feijão-de-porco, com 0,2 dag. $\mathrm{kg}^{-1}$. $\mathrm{O}$ milheto consorciado com guandu-anão e solteiro, bem como o feijão-de-porco consorciado com milheto e em cultivo solteiro não diferiram significativamente do primeiro, porém, também não apresentaram diferença significativa para o guandu-anão consorciado com milheto (Tabela 4). Esta inferioridade do guandu com relação ao teor de Mg corrobora com os dados encontrados por Carvalho (2000), que encontrou maior teor do elemento no milheto com 0,33 dag. $\mathrm{kg}^{-1}$, contra 0,29 dag. $\mathrm{kg}^{-1}$ no guandu e por Alvarenga et al. (1995), que verificaram superioridade do feijão-de-porco em relação ao guandu $\left(0,22\right.$ dag. $\mathrm{kg}^{-1}$ contra 0,13 dag. $\left.\mathrm{kg}^{-1}\right)$.

Os teores de $\mathrm{Mg}$ verificados para o milheto foram inferiores aos encontrados por Carvalho (2000), Oliveira (2001) e Moraes (2001), o que pode ser explicado pela menor concentração do elemento no solo do presente trabalho, de $0,7 \mathrm{cmol}_{c} \cdot \mathrm{dm}^{-3}$, considerada média. No feijão-deporco, os teores de $\mathrm{Mg}$ se inserem nos verificados por Araújo e Almeida (1993), Favero et al. (2000) e Oliveira (2001), os quais foram em média 0,25 dag.kg-1 . Para o guandu, os teores estão dentro dos encontrados por Favero et al. (2000) e Alcântara et al. (2000) com 0,21 dag. $\mathrm{kg}^{-1} \mathrm{e}$ Carvalho (2000), com média de 0,19 dag. $\mathrm{kg}^{-1}$, tendo todos estes autores utilizado cultivares de porte alto.

Com relação ao S, os maiores teores foram observados no milheto, tanto em cultivo solteiro quanto consorciado, com destaque para este último. O feijão-de-porco e o guandu-anão não diferiram entre si (Tabela 4).

$\mathrm{O}$ teor de $\mathrm{S}$ verificado para o milheto foi superior ao encontrado por Carvalho (2000), inferior ao observado por Moraes (2001) e próximo ao encontrado por Oliveira (2001). Porém, diferentemente do presente trabalho, o último autor não encontrou diferença significativa entre os teores do elemento no milheto e no feijãode-porco. No guandu, o teor do elemento foi muito próximo dos encontrados por Alcântara et al. (2000) e Carvalho (2000), não tendo o último encontrado diferença significativa entre os teores de $\mathrm{S}$ do milheto e do guandu. Cabe lembrar que as cultivares utilizadas por esses autores eram de porte alto.

Pelo confronto entre os teores de nutrientes obtidos neste trabalho e aqueles obtidos por outros autores, verifica-se uma grande variabilidade dentro das espécies, o que se deve, em grande parte, às diferenças entre a fertilidade dos solos nos quais os trabalhos foram desenvolvidos, podendo-se inferir que a eficiência da reciclagem de nutrientes das plantas de cobertura do solo, depende muito da fertilidade pré-existente no mesmo.

\section{CONCLUSÕES}

Entre os consórcios, o milheto + feijão-de-porco apresentou maior produção de fitomassa.

O guandu-anão mostrou-se inadequado para uso na região, na época da semeadura estudada.

As leguminosas apresentaram maiores teores de $\mathrm{N}$ e Ca e o milheto maiores teores de $\mathrm{K}$.

O feijão-de-porco em consórcio com milheto apresentou uma tendência ao maior teor de $\mathrm{K}$.

\section{REFERÊNCIAS BIBLIOGRÁFICAS}

ALCÂNTARA, F. A. de. Adubação verde na recuperação da fertilidade de um Latossolo vermelho escuro degradado. Pesquisa Agropecuária Brasileira, Brasília, v. 35, n. 2, p. 277-288, 2000.

ALVARENGA, R. C. et al. Características de alguns adubos verdes de interesse para conservação e recuperação de solos. Pesquisa Agropecuária Brasileira, Brasília, v. 30, n. 2, p. 175-185, 1995.

AMABILE, R. F. Comportamento de adubos verdes em épocas de semeadura nos cerrados do Brasil central. 1996. 123 f. Dissertação. (Mestrado em fitotecnia) - Escola Superior de Agricultura Luiz de Queiroz USP, Piracicaba, 1996.

AMADO, T. J. C.; MIELNICZUK, J. Estimativa da adubação nitrogenada para o milho em sistemas de manejo e culturas de cobertura do solo. Revista Brasileira de Ciência do Solo, Campinas, v. 24, p. 553560, 2000.

AMADO, T. J. C.; MIELNICZUK, J.; FERNANDES, S. B. V. Leguminosas e adubação mineral como fontes de nitrogênio para o milho em sistemas de preparo do solo. Revista Brasileira de Ciência do Solo, Campinas, v. 24, p. 179-189, 2000.

ARAÚJO, A. P.; ALMEIDA, D. L. de. Adubação verde associada a fosfato de rocha na cultura do milho. Pesquisa Agropecuária Brasileira, Brasília, v. 28, n. 2, p. 245-251, 1993.

BASSO, C. J.; CERETTA, C. A. Manejo do nitrogênio no milho em sucessão a plantas de cobertura de solo sob plantio direto. Revista Brasileira de Ciência do Solo, Campinas, v. 24, p. 905-915, 2000. 
CALEGARI, A. et al. Caracterização das principais espécies de adubo verde. In: . Adubação verde no sul do Brasil. Rio de Janeiro: AS-PTA, 1992. p. 207-327.

CARVALHO, M. A. C. Adubação verde e sucessão de culturas em semeadura direta e convencional em Selvíria-MS. 2000. 189 f. Tese (Doutorado em Produção vegetal) - Faculdade de Ciências Agrárias e Veterinárias, Universidade Estadual de São Paulo, Jaboticabal, 2000.

CERETTA, C. A. et al. Fornecimento de nitrogênio por leguminosas na primavera para o milho em sucessão nos sistemas de cultivo mínimo e convencional. Revista Brasileira de Ciência do Solo, Campinas, v. 18, p. 215-220, 1994.

EMPRESA BRASILEIRA DE PESQUISA AGROPECUÁRIA. Sistema brasileiro de classificação de solos. 2. ed. Brasília, 2000. 412 p.

FAVERO, C. et al. Crescimento e acúmulo de nutrientes por plantas espontâneas e por leguminosas utilizadas para adubação verde. Revista Brasileira de Ciência do Solo, Campinas, v. 24, p. 171-177, 2000.

GIACOMINI, S. J. et al. Matéria seca, relação C/N e acúmulo de nitrogênio, fósforo e potássio em misturas de plantas de cobertura de solo. Revista Brasileira de Ciência do Solo, Brasília, v. 27, p. 325-334, 2003.
MALAVOLTA, E.; VITTI, G. C.; OLIVEIRA, S. A. Avaliação do estado nutricional das plantas: princípios e aplicações. Piracicaba: POTAFOS, 1997. 319 p.

MORAES, R. N. de S. Decomposição de palhadas de sorgo e milheto, mineralização de nutrientes e seus efeitos no solo e na cultura do milho em plantio direto. 2001. 90 p. Dissertação (Mestrado em fitotecnia) Universidade Federal de Lavras, Lavras, 2001.

OLIVEIRA, T. K. de. Plantas de cobertura em cultivo solteiro e consorciado e seus efeitos no feijoeiro e no solo em plantio direto. 2001. 109 p. Dissertação (Mestrado em fitotecnia) - Universidade Federal de Lavras, Lavras, 2001.

SANTOS, C. T. C.; CARVALHO, G. J. de. Avaliação de leguminosas utilizadas para adubação verde, cultivadas no inverno e no verão sem adubação química na região de Lavras. In: CONGRESSO DE INICIAÇÃO CIENTÍFICA DA UFLA, 12., 1999, Lavras. Anais... Lavras: Ufla/PRP, 1999. p. 43.

TEIXEIRA, C. M.; CARVALHO, G. J. de. Estudo do comportamento do sorgo, milheto e aveia preta na produção de forragem e matéria seca para cobertura morta do solo no sistema de plantio direto. In: CONGRESSO DE INICIAÇÃO CIENTÍFICA DA UFLA, 12., 1999, Lavras. Anais... Lavras: Ufla/PRP, 1999. p. 44. 